\title{
Tracing the Evolution of Transfer of Training: A Review Article
}

\author{
Asif Ali Rahman* \\ Faculty of Education, University of Regina, Canada
}

Submission: June 26, 2020; Published: July 07, 2020

"Corresponding author: Asif Ali Rahman, Faculty of Education, University of Regina, Canada

Abstract

This article presents an evolution of transfer of training from 1901 to 2020. The discussion about transfer of training begins with a brief introduction to the framework about the transfer process, followed by the literature review on transfer of training. For the purpose of simplicity, the literature review is broadly discussed based on three eras of research: 1901 to 1988, 1988 to 2008, and 2008 to 2020. During the entire discussion, the results of the research conducted in the three eras are compared and the changing research trends from 1901 to 2020 are discussed.

Keywords: Transfer of training; Human resource development; Management; Education; Training

\section{Introduction}

Over the past few decades, extensive research has been conducted on transfer of training to increase the transfer of knowledge, skills and attitudes acquired in a training context to a job. Transfer of training is defined as the degree to which trainees effectively apply the knowledge, skills, and attitudes gained in a training context to the job $[1,2]$. In spite of these research efforts, and a heightened interest in the concept, the rate of transfer of training by employees to their jobs was estimated at $15-30 \%$ three decades ago, and that rate is still the same today [3-5]. This is called the transfer problem. The 'Transfer Problem' has existed for more than three decades now. One of the reasons is probably the lack of proper direction, a framework or a consolidation of the available literature. Baldwin \& Ford [6] conducted a comprehensive literature review on transfer of training for the first time in 1988. The period covered in their review was from 1901 to 1988, and based on their review, the authors offered some suggestions for further research. Based on the research gaps they identified, the authors developed a framework for conducting research on the effects of trainee characteristics on transfer of training in organizations. Baldwin \& Ford [6] literature review sparked a new interest in transfer of training in the research and academic circles. A number of researchers conducted research and published on the subject over the next 20 years. Baldwin \& Ford [7] conducted another literature review in 2008. They called their work an updated literature review to include the new literature that had emerged from 1988 to 2008. They offered a critical analysis of the literature at that time and offered suggestions for further research. The next literature review by Baldwin and Ford is due in 2028. Since 2008, numerous researchers have conducted research on transfer of training. This article traces the evolution of transfer of training from 1901 to 2020.

\section{A framework of the transfer of training process}

Baldwin \& Ford [6] developed a framework in 1988 that explained the transfer of training process. They claimed that it was very important to understand the transfer of training as well as the factors that affect the transfer process to address the 'transfer problem' in organizations. They described the transfer process in the following way:

\section{i. Training inputs}

a) Training Design; incorporation of the learning principals, the sequencing of training material and the job relevance of training content.

b) Trainee Characteristics; ability, motivation and personality traits.

c) Work Environment Characteristics: supervisory or peer support and constraints \& opportunities to perform learning behavior. 


\section{ii. Training outcomes}

a) Actual learning that occurred during the training.

b) Retention of that material after the program completed.

\section{iii. Conditions of transfer}

a) Generalization of the material learned in the training to the job context.

b) Maintenance of a learned material over a period of time on the job.

The model indicates that training inputs and training outcomes have a direct or indirect impact on conditions of transfer (Figure 1). The six linkages shown in the above model are very important in understanding the transfer process. For example, linkage 6 is a representation of how training outcomes (learning and retention) can have a direct effect on the conditions of transfer [6]. Trainee characteristics and work environment characteristics represented by linkages 4 and 5 also have a direct impact on the conditions of transfer regardless of their direct impact on the training outcomes of learning and retention (linkages 2 and 3). For example, welllearned skills might not be maintained on the job due to the lack of supervisory or peer support [6]. Finally, the three training inputs of trainee characteristics, training design, and work environment have a direct impact on the training outcomes of learning and retention (linkages 1, 2 and 3) and an indirect impact on conditions of transfer. Baldwin \& Ford [6] identified major empirical studies on the transfer of training process based on their framework. The literature was based on the research on the effects of training design, trainee characteristics or work-environmental characteristics (training inputs) on learning and retention of the training material (training outcomes) or generalization and maintenance of training (conditions of transfer). Their review and analysis of the major empirical studies focused specifically on the 'transfer problem' in organizations.

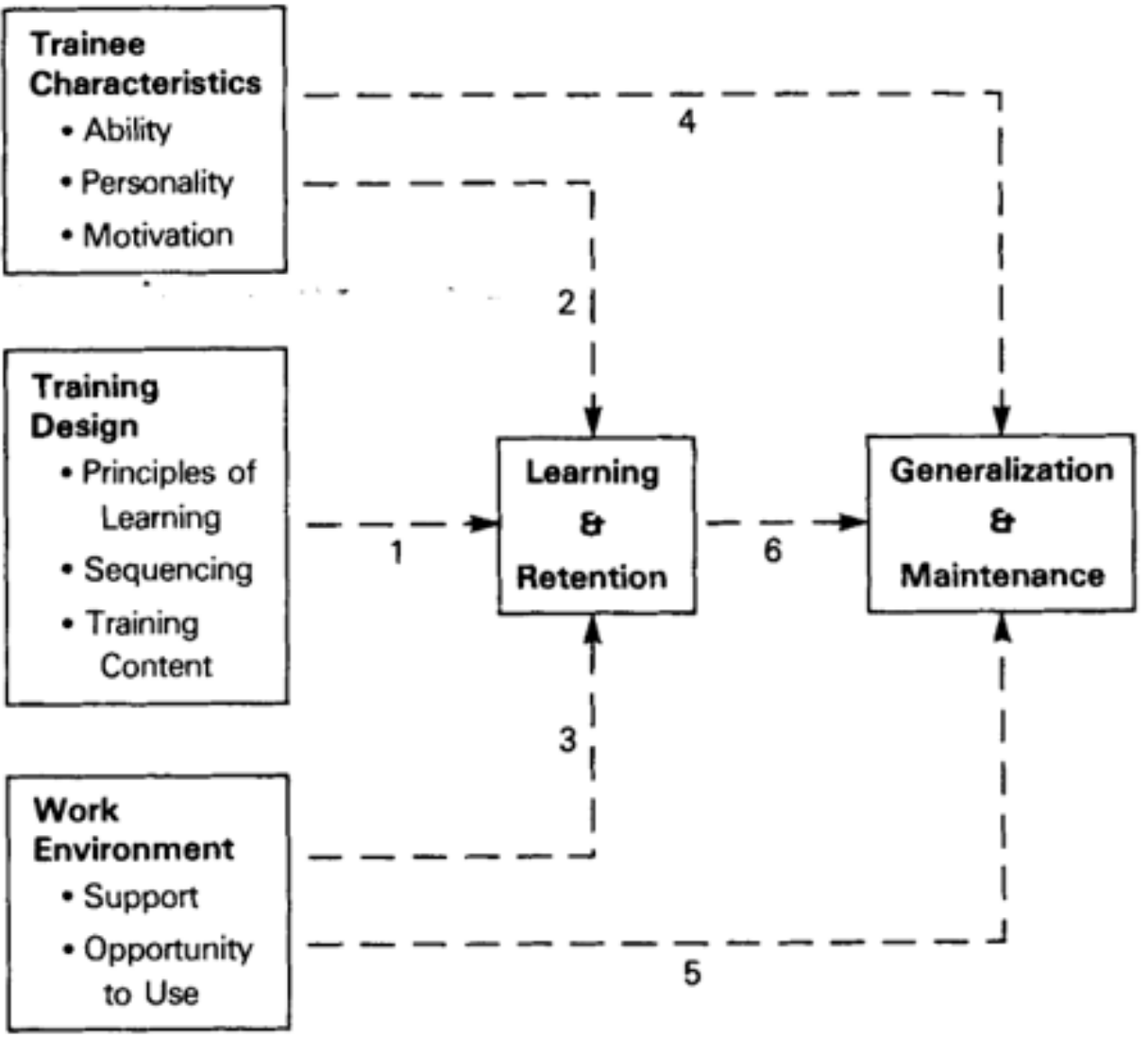

Source: Baldwin and Ford [6]

Figure 1: A Model of the Transfer Process [6]. 


\section{Training design}

A considerable number of the empirical studies that Baldwin \& Ford [6] reviewed focused on training design issues. Four principles were identified in the literature, which are identical elements, the teaching of general principals, stimulus variability, and various conditions of practice. These four principles are discussed below:

a) Identical elements: Thorndike and Woodworth [8] were the first authors to introduce the concept of identical elements. According to the identical elements theory, if the training environment, training interactions, and training material match the performance expectations, then the transfer of training would occur [8-11]. Later, other researchers revealed that the use of identical elements increased the retention of motor skills $[12,13]$ and verbal behaviors [14,15].

b) The teaching of general principles: The second principle that was identified in the literature is teaching of general principles. According to this principle, it is very important to teach the underlying principles and general rules of the training content in addition to the applicable skills [6]. For example, while explaining the technical aspects of underwater shooting, Judd [16] and Hendrickson, Schroeder [17] demonstrated how important it was to know the underlying general rules and principles of the underwater shooting. Crannell [18] argued the same point that the underlying general rules and principles were very important by conducting experiments on subject's ability to learn through card sorting tricks. Goldbeck, Bernstein [19] discovered that the technicians of malfunctioning electronic equipment who clearly understood the underlying functioning principles of the electronic equipment were in a better position to solve problems than the technicians who were not [6].

c) Stimulus variability: Ellis [20] state in Baldwin \& Ford [6] that stimulus variability is a notion in which different kinds of stimuli are used to conduct training. For example, when different examples are used to explain a concept in training rather than using the same example repeatedly, the trainees learn more $[20,21]$. The principle of stimulus variability has also received empirical support from other researchers. For example, Shore \& Sechrest [22] found that when different examples were used in a training, each example enhanced the learning a little bit more.

Various conditions of practice; Conditions of practice refer to certain design issues such as:

a. Massed or distributed learning: Massed learning is a concept in which a learner learns large quantities of content in short periods of time where distributed learning is a concept in which a learner learns small quantities of content in longer periods of time in distributed intervals. Massed or distributed learning is concerned with the degree to which a training can be divided into segments. Baldwin \& Ford [6] argue that massed or distributed learning is very important in a training program for positive transfer of training. They offered a number of examples and referred to a number of researchers to support this argument. For example, some researchers indicated that distributed learning was more helpful in retaining the knowledge transferred longer than massed learning [23, 24]. Other researchers provided evidence that difficult and complex tasks resulted in a higher performance, which could only be done through massed practice sessions, followed by brief sessions with more rest periods [25].

b. Whole or part training: Whole training is a training in which the whole content is delivered at once. Whole training is best for content that is high in organization and low in complexity. On the other hand, part training is a training in which the whole content is divided into parts. Part training is best for content that is low in organization and high in complexity. Therefore, whole or part training refers to the idea of delivering the entire training material at once or dividing the material into parts to be learned separately. Researchers have suggested that imparting the whole training material at once was beneficial when (1) the learners were of high caliber and highly intelligent, (2) there was distributed learning rather than massed learning, and (3) the training material was organized around a task that had low complexity [24]. On the other hand, part training was ideal when (1) the learners were not of high caliber and (2) there was massed learning rather than distributed learning.

c. Feedback: According to Baldwin \& Ford [6], feedback refers to the critical advice given to the trainees about their performance or results during the training. Wexley \& Thornton [26] argued in Baldwin \& Ford [6] that the timing of the feedback was very important in determining the effects of training. Some researchers also suggested that the optimal specificity of the feedback actually depended on the trainees and the stage of learning in which they were, but the empirical evidence was lacking [27].

d. Overlearning: McGehee \& Thayer [28] stated in Baldwin \& Ford [6] that overlearning refers to the idea of trainees being taught even after the task has been successfully completed. Research suggested that the greater the overlearning, the greater was the degree of positive transfer of training [29-31]. Baldwin and Ford also gave another recent example of Hagman \& Rose [32] who provided empirical evidence in support of the value of overlearning in military training contexts.

\section{Work-environment characteristics}

Work-environment can be defined as the surroundings where an employee works. Work-environment characteristics can be defined as the positive or negative attributes of the work-environment. According to Baldwin \& Ford [6], although the practitioners' literature stresses the relationship between positive transfer of training and the work environment, the research indicates no empirical evidence to support such an argument [33]. For example, management researchers such as Baumgartel \& Jeanpierre [34], Baumgartel, Reynolds [35], Baumgartel, Sullivan [36] explained how a conducive work 
environment acts as a catalyst for managers to translate their training skills into productive job performance, leading to a positive transfer of training. Hand, Richards [37] in Baldwin \& Ford [6] argue that a retention of training skills even after 18 months of training was due to certain organizational decisions such as salary and promotion, which motivated the employees to learn more. In their research on different management styles, Huczynski \& Lewis [38] found out that management styles that allowed employees to discuss training with their managers before the start of their training entailed maximum transfer of training. According to Baldwin and Ford, the essence of their review was not to argue and debate each and every point of view about the transfer problem from 1901 to 1988, but to provide an overall critique of the literature and offer some recommendations for the further research. The recommendations for further research that Baldwin \& Ford [6] offered, paved the way for other researchers to jump into the field. As a result, transfer of training became an important arena of research and practice over the next 20 years beginning in 1988 [7]. This review of transfer of training literature showed that an increasing awareness of the "transfer problem" exist in organizations. However, while a concern over the transfer problem exist, there was a little understanding of the transfer problem. Different researchers provided different reasons for a lack of understanding of the transfer problem.

Post-1988 literature revealed four new research trends [7]. Firstly, researchers had moved beyond such simple experiments as learning and motor tasks and were studying more complex and authentic training content. Secondly, there was increasing evidence of the use of interventions especially designed to increase transfer outcomes. Thirdly, researchers were more inclined towards looking outside the training design and more towards pre- and posttraining influences. Finally, there was a greater variety of criterion measures to evaluate transfer of training. Where the research prior to 1988 was using simple memory and motor tasks as laboratory experiments, and students comprised much of the sample used in those studies, the post-1988 research focused on more complex transfer related issues such as trainee characteristics, training environment, and training context. The use of simple memory and motor tasks was not realistic since training entailed much more complex tasks. Similarly, the predominant use of student samples limited generalizability of the findings. In the post-1988 research, "business employees and managers, health professionals (e.g. nurses and doctors), public safety workers and technical or computer specialists" were used in research samples [7]. An increase in diverse samples and authentic skills was a positive trend since it had a tendency for an increased generalizability of the transfer of training findings. Although a diversity of sampling, authentic and complex skills was a positive sign, there was still considerable work left to be done in this arena. For example, there was still a need for the development of taxonomies and categories for different kinds of skills and knowledge training that could be useful in transfer studies. Moreover, some of the important facets of transfer of training area were still missing from the transfer of training research, such as little research on the factors affecting the objectives of training in question [7]. Thus, the scholars concluded that it would be unwise and illogical to provide any kind of guidance to the training professionals without further classification on exactly what is being trained and what training objectives were being sought. According to most of the scholars, "The movement toward the study of authentic training content in naturally occurring contexts (not contrived for research studies) has been one of the most positive shifts in transfer research of the last two decades" [7]. This movement must continue and inform the further research to better understand transfer of training. Moreover, one of the most prominent limitations of the pre-1988 literature was that it was not action oriented. Most of the studies of the time stopped a little short of identifying, describing or measuring the factors that affected transfer of training. The only studies that dealt with a little change or intervention were the ones that were dealing with training design [7]. Furthermore, it was not just the tools used during the training that were important for transfer to take place, but the post-training assessments, feedback and goal setting were also essential. They provided examples of Wexley \& Nemeroff [39] and Reber \& Wallin [40] who showed that post-training assessments, goal setting, and feedback caused better performance and transfer of training. After 1988, the research focus shifted from the research design to preand post-training context. For example, Karl \& Ungsrithong [41] found that the optimistic training preview had a positive impact on overall training in the form of motivation, learning, outcome expectations, feedback to training, and transfer of training. Other researchers focussed on how training could be framed prior to a training event. For example, Martocchio [42] in Baldwin, Ford [7] examined a computer program to find out if the use of computers had a positive impact on transfer of training. Martocchio found that computer had a positive impact on transfer of training.

Interventions in the design of training might also include some unique and intriguing error training/management. For example, Heimbeck, Frese [43] in Baldwin, Ford [7] allowed trainees to make mistakes and errors in the hope that such errors would result in the most lasting transfer of training outcomes. Similarly, Gully, Payne [44] in Baldwin et al. [7] examined the effectiveness of error training in trainees in decision making with different levels of "cognitive ability, openness to experience, and conscientiousness" [7]. They discovered that error training/ management with trainees of different levels of cognitive ability, openness to experience, and conscientiousness can have different transfer of training outcomes. A considerable amount of research in behavior modeling was conducted from 1988 to 2008. For example, Baldwin [45] "examined the use of negative and positive transfer model displays on outcomes of a behavior modeling training program" [7]. They discovered that in a training of assertive communication, trainees who displayed both negative and positive transfer had greater retention and a higher level of generalization of trained skills. Similarly, Holladay \& Quiñones [46] examined the relationship between near and far transfer, 
self-efficacy and practice variability as cited in Baldwin, Ford [7], and "They found that variable practice was superior to constant practice in promoting high levels of self-efficacy. In addition, selfefficacy served as a mediator between practice variability and far transfer" [7].

Taylor et al. [47] did a meta-analysis of 66 studies and evaluated the effects of behavior modeling training on job behavior [7]. They found that training retention was greatest when mixed (negative and positive) transfer models were presented. Similar to pretraining interventions, research on post-training interventions was also dramatically increased from 1988 to 2008. Baldwin et al. concluded that studies that explored intentional interventions had greater potential to add to the body of knowledge about transfer of training and cautioned researchers to be mindful of those intentional interventions in their studies. Pre- and post-training influences play a significant role in the transfer of training. Transfer of training could only occur after the training but surprisingly, pre-1988 research focused entirely on the nature of the training itself and not the transfer of training. However, very limited research indicated that the trainees, their traits and their ability to transfer skills learned in trainings to job performance were important predictors of the transfer process. Baldwin et al. state, "The notion that performance, in any setting, is a function of ability, motivation, and opportunity is one of the most enduring conceptualizations in industrial/organizational psychology" [7]. In addition, Facteau, Dobbins [48] in Baldwin, Ford [7] argued that trainees needed three traits for transfer to occur:

a) Their ability to learn.

b) An effort to learn and to improve.

c) A belief that a changed performance leads to valued outcomes.

Moreover, drawing on Bandura [49] and his social cognitive theory, a number of behavioral studies have been conducted to demonstrate the effects of behaviour on learning as well as transfer of self-efficacy and its variants. Other studies have shown various pre- and post-training factors that could influence the transfer of training. For example, the choice to attend a training program, motivation not only to learn but also to transfer, motivation to improve job performance, work environment, quality of worker/ supervisor relationship, and an open-mindedness to change are all essential predictors of transfer of training. Thus, transfer of training factors exists in training design and in pre- and posttraining activities. The factors indicate that continued research that is multi-disciplinary and multi-dimensional would be most useful to fully understand transfer of training [7]. Before 1988, the research on transfer of training was very limited because of short-term single source measurement of transfer. Baldwin \& Ford [6] noted that a number of problems existed with the pre-1988 research and these problems mostly related to the measurement of training outcomes. However, after 1988, two advances that occurred in the transfer of training research were (1) a broadening of the measurement of outcomes, and (2) a collection of multiple tools for the measurement of outcomes over time. Moreover, transfer of training research started including concepts like selfefficacy [50,51,52-55]. Research showed that the employees having self-efficacy were more likely to perform more tasks and attempted to do more difficult and complex tasks [7]. Thus, self-efficacy was an important variable in the understanding of transfer of training, and self-efficacy was an important example of how theoretical and empirical research helped in widening the number of variables in the measurement of the outcomes of transfer of training [7].

The second important trend that Baldwin, Ford [7] found in the research after 1988 was that most of the researchers had started conducting longitudinal studies, that is, research conducted over a period of time ranging from one week to a month or a couple of months to one year or a couple of years. One of the best examples of such research was by Hazucha, Hezlett [56]. They conducted a longitudinal study that measured the outcomes of training multiple times over two years. The main objective of their research was to investigate the relationship between skill development, development efforts, and the environmental support for the developmental efforts. A longitudinal study gave the scholars a change to measure the development of skills, the efforts being used for development, and the environmental support provided over the span of two years. The post-1988 research on transfer of training took an interesting turn. The post-1988 research was interesting because a number of new developments took place and the research on transfer of training took some new directions. These new developments and directions are discussed under four themes, which are an understanding of learning, the trainees, training design, and the training context. An Understanding of Learning: The individual was not the focus in pre-1988 research on transfer of training, and so an understanding of learning was not a major focus of research during that period. Much of the laboratory experiments conducted by researchers were about memory and motor skills, and the samples used were students. The next 20 years (1988 - 2008) led to more interest in understanding how individuals learn. More diverse groups, like managers, professionals, nurses, and doctors were studied, which made the research results more generalizable. Similarly, more authentic and complex human learning behaviours were studied. These trends were a positive sign since they made transfer of training research more generalizable and useful. In the next decade (2008 - 2018), transfer of training was defined as the application of newly learned knowledge, skills, attitudes, and behaviours to the workplace $[57,58]$. However, Tonhäuser \& Büker indicate that for research on transfer of training to be complete, researchers should consider the pedagogical and psychological aspects of transfer problem, including whether the trainees have the ability to transfer newly learned knowledge, skills, attitudes, and behaviour to the workplace. Tonhäuser \& Büker refer to this 
ability transfer competence, which is a prerequisite to a change in working behaviour. Therefore, the discussion on the transfer problem became centered around the individual rather than around the measurement of training outcomes. Thus, transfer of training becomes complete only when the individual learning patterns are taken into account in the transfer process $[59,60]$.

Another interesting issue in the understanding of transfer research was the limited research in the area of information technology and its impact on transfer of training. Research on the impact of information technology on transfer of training emerged in the early 1990s, even though considerable research in the area appeared only after 2008. For example, according to Hughes, Anthony Day [61], considerable complexity in transfer research in areas such as computer software, navigation skills, and video games exist. Thus, information technology can have an impact on learning and enhancement of cognitive abilities. For example, in this era of apps, when mobile devices are widely available, along with the extensive use of educational apps and YouTube videos, people learn faster and quicker compared to use of the traditional training approaches $[62,63]$. Therefore, the use of information technology, mobile devices, and mobile aps help to increase the transfer of training.

The Trainees: Although some researchers such as Robinson [64] and Trost [65] believed that various trainee characteristics were important for the transfer of training, Baldwin \& Ford [6] argued that the main trainee characteristics of "ability, personality and motivational effects" did not have enough empirical evidence. Over the next 20 years (1988-2008), more research on trainees and trainee characteristics became available. For example, Facteau, Dobbins [48] in Baldwin, Ford [7] argued that trainees should have three traits for transfer to occur. The trainees should have an ability to learn, they should make an effort to learn and improve their performance, and they should believe that a changed performance would lead to valued outcomes. Further, during the post-2008 research, transfer research related to the trainees and trainee characteristics was broadened. According to Bell, Tannenbaum [57], researchers moved beyond just using expectancy theory in transfer research. Instead, they started using multiple theories like "the theory of planned behavior, proactive personality, social exchange, career motivation theory, personenvironment fit, and deprivation theory" [57]. In another research, Dragoni, Oh [66] found a positive relation between self-efficacy, stability, and learning orientation to self-perceived knowledge role. Another research indicated that self-efficacy and learning orientation shielded trainees from stresses from challenging job experiences [67]. During the post-2008 transfer research period, numerous experiments ranging from instructional methods and training through e-learning, simulations, and games and their effects on various trainee characteristics were conducted. These experiments measured trainee self-efficacy, cognitive ability, and goal orientation in the training process. These experiments have had a direct influence on the trainees' learning ability, and a direct impact on transfer of training $[57,61]$. In short, post-2008 transfer research era marked the undertaking of experiments related to the broadening of trainee characteristics. The experiments strove to explore the relationships between self-efficacy, cognitive ability, and goal orientation.

Training Design: A considerable number of empirical studies before 1988 focused on training design [6]. Four principles were identified in the literature, which were identical elements, the teaching of general principals, stimulus variability, and various conditions of practice [6]. Pre-1988 research was also not action oriented, as it was limited to lab experiments only. From 1988 to 2008, a heightened interest on action research emerged, with an increased focus on transfer interventions and their effects on learning behaviours. During the period from 1988 to 2008, training design models were developed to test various forms of training interventions that could lead to an increase in transfer of training. The last decade (2008-2018) witnessed an increased reliance on technology and the use of eLearning tools. That trend shifted the focus of training and training design to learner centered training designs, which gave the learners control over their learning [68]. Another interesting issue that emerged in research during the decade was a comparison of different technologies used for training and training design to determine their value. Researchers argued the more technologies used in training design and delivery, the more effective the training became Brown, Charlier, \& Pierotti [69,70-73]. Pedagogical features that governed the e-learning technologies used in training became much more important Bell \& Federman [74].

Training Context: The training context was not studied in depth before 1988. The only factor that was considered the training context during that period was the work-environment characteristics. In addition, since researchers were focused on understanding the nature of training, limited research was conducted on transfer of training during that period [6]. According to Baldwin, Ford [7], the training context was an area in need of considerable research during that period. During the decade from 2008 - 2018, many aspects of the effects of training context on transfer of training remain unknown such as the personal or professional environment related circumstances that can affect training before, during, and after the training. Research on contextual factors such as the personal or professional environment related circumstances that can affect training before, during, and after the training remains scarce as of 2020.

\section{Conclusion}

This review article traces the evolution of transfer of training from 1901 to 2020 . The article presents an analysis of the research trends from 1901 to 2020 giving special emphasis to various competing philosophies and avenues for future research. The article also presents itself as a comprehensive literature review on the field for future empirical studies. 


\section{Annals of Social Sciences \& Management studies}

\section{References}

1. Wexley KN, Latham GP (1981) Developing and training human resources in organizations. Glenview, IL: Scott Foresman.

2. Newstrom JW (1984) A role-taker/time differentiated integration of transfer strategies in 1984 meeting of the American Psychological Association (APA). Toronto, Ontario, Canada.

3. Holton E (2008) Why training transfer is a critical problem in Transfer of Training Channel. YouTube.

4. Khalid M, Hanif A, Laila U (2017) Transfer of training \& the challenges: NADRA A case study. International Review of Management and Business Research 6(1): 274-288.

5. Cheema F-e-A, Syed NA (2014) Issues of transfer of training from the training houses to the line department: A case of government sector department in Pakistan. IBT Journal of Business Studies 9(1): 150-158.

6. Baldwin TT, Ford JK (1988) Transfer of training: A review and directions for future research. Personnel Psychology 41(1): 63-105.

7. Baldwin TT, Ford JK, Blume BD (2009) Transfer of training 1988-2008: An updated review and new agenda for future research. in International review of industrial and organizational psychology, Hodgekinson GP Ford JK, (Edts.), Wiley: Chichester, UK, p. 41-70.

8. Thorndike EL, Woodworth RS (1901) The influence of improvement in one mental function upon the efficiency of other functions. Psychological Review 8(3): 247-261.

9. Thorndike EL, Woodworth RS (1901) The influence of improvement in one mental function upon the efficiency of other functions II: The estimation of magnitudes. Psychological Review 8(4): 384-395.

10. Thorndike EL, Woodworth RS (1901) The influence of improvement in one mental function upon the efficiency of the other functions III Functions involving attention, observation, and discrimination. Psychological Review 8: 553-564.

11. Saks AM, Belcourt M (2006) An investigation of training activities and transfer of training in organizations. Human Resource Management 45(4): 629-648

12. Crafts LW (1935) Transfer as Related to Number of Common Elements. Journal of General Psychology 13(1): 147-158.

13. Gagné RM, Baker KE, Foster H (1950) On the relation between similarity and transfer of training in the learning of discriminative motor tasks. Psychological Review 57(2): 67-79.

14. Duncan CP (1953) Transfer in motor learning as a function of degree of first-task learning and inter-task similarity. Journal of Experimental Psychology 45(1): 1-11.

15. Underwood BJ (1951) Associative transfer in verbal learning as a function of response similarity and degree of first-line learning. Journal of Experimental Psychology 42: 44-53.

16. Judd CH (1908) The relation of special training and general intelligence. Educational Review 36: 28-42.

17. Hendrickson G, WH Schroeder (1941) Transfer of training in learning to hit a submerged target. Journal of Educational Psychology 32(3): 205-213.

18. Crannell CW (1956) Transfer in problem solution as related to the type of training. Journal of General Psychology 54(1): 3-14.

19. Goldbeck RA, Bernstein BB, Hillix WA, Marx MH (1957) Application of the half-split technique to problem-solving tasks. Journal of Experimental Psychology 53(5): 330-338.

20. Ellis HC (1965) The transfer of learning. New York: Macmillan.

21. Duncan CP (1958) Transfer after training with single versus multiple tasks. Journal of Experimental Psychology 55(1): 63-72.

22. Shore E, Sechrest L (1961) Concept attainment as a function of number of positive instances presented. Journal of Educational Psychology 52(6): 303-307.

23. Briggs GE, JC Naylor (1962) The relative efficiency of several training methods as a function of transfer task complexity. Journal of Experimental Psychology 64(5): 505-512.

24. Naylor JC, Briggs GE (1963) Effects of task complexity and task organization on the relative efficiency of part and whole training methods. Journal of Experimental Psychology 65(3): 217-224.

25. Holding DH (1965) Principles of training, Pergamon Press: London.

26. Wexley KN, Thornton CL (1972) Effect of Verbal Feedback of Test Results upon Learning. The Journal of Educational Research 66(3): 119121.

27. Blum ML, Naylor JC (1968) Industrial psychology: Its theoretical and social foundations. Harper Row, New York.

28. McGehee W, Thayer PW (1961) Training in Business and Industry. Wiley, New York

29. Atwater SK (1953) Proactive inhibition and associative faciliation as affected by degree of prior learning. Journal of Experimental Psychology 46(6): 400-404

30. Gagné RM, Foster H (1949) Transfer to a motor skill from practice on a pictured representation. Journal of Experimental Psychology 39(3): 342-354.

31. Mandler G (1954) Transfer of training as a function of degree of response overlearning. Journal of Experimental Psychology 47(6): 411417.

32. Hagman JD, Rose AM (1983) Retention of Military Tasks: A Review. Human Factors: The Journal of the Human Factors and Ergonomics Society 25(2): 199-213.

33. Eddy WB, Glad DD, Wilkins DD (1967) Organizational effects on training. Training and Development Journal 22(2): 36-43.

34. Baumgartel H, Jeanpierre F (1972) Applying new knowledge in the back-home setting: A study of Indian managers' adoptive efforts. The Journal of Applied Behavioral Science 8(6): 674-694.

35. Baumgartel H, Reynolds M, Pathan R (1984) How personality and organizational-climate variables moderate the effectiveness of management development programmes: A review and some recent research findings. Management and Labour Studies 9(1): 1-16.

36. Baumgartel H, Sullivan GJ, Dunn LE (1978) How organizational climate and personality affect the pay-off from advanced management training sessions. Kansas Business Review 5: 1-10.

37. Hand HH, Richards MD, Slocum JW (1973) Organizational Climate and the Effectiveness of a Human Relations Training Program. The Academy of Management Journal 16(2): 185-195.

38. Huczynski AA, Lewis JW (1980) An empirical study into the learning transfer process in management training. Journal of Management Studies 17(2): 227-240.

39. Wexley KN, Nemeroff WF (1975) Effectiveness of positive reinforcement and goal setting as methods of management development. Journal of Applied Psychology 60(4): 446-450.

40. Reber RA, Wallin JA (1984) The Effects of Training, Goal Setting, and Knowledge of Results on Safe Behavior: A Component Analysis. Academy of Management Journal 27(3): 544-560

41. Karl KA, Ungsrithong D (1992) Effects of Optimistic Versus Realistic Previews of Training Programs on Self-Reported Transfer of Training. 


\section{Annals of Social Sciences \& Management studies}

Human Resource Development Quarterly 3(4): 373-384.

42. Martocchio JJ (1992) Microcomputer usage as an opportunity: The influence of context in employee training. Personnel Psychology 45(3): 529-552.

43. Heimbeck D Frese M, Sonnentag S, Keith N (2003) Integrating errors into the training process: The function of error management instructions and the role of goal orientation. Personnel Psychology 56(2): 333-361.

44. Gully SM, Payne SC, Koles KLK, Whiteman JAK (2002) The impact of error training and individual differences on training outcomes: An attribute-treatment interaction perspective. Journal of Applied Psychology 87(1): 143-155

45. Baldwin TT (1992) Effects of alternative modeling strategies on outcomes of interpersonal-skills training. Journal of Applied Psychology $77(2): 147-154$

46. Holladay CL, Quiñones MA (2003) Practice variability and transfer of training: the role of self-efficacy generality. Journal of applied psychology 88(6): 1094-1103.

47. Taylor PJ, Russ-Eft DF, Chan DWL (2005) A Meta-Analytic Review of Behavior Modeling Training. Journal of Applied Psychology, 90(4): 692-709.

48. Facteau JD, Gregory H Dobbins, Joyce EA Russell, Robert T Ladd, Jeffrey D Kudisch (1995) The influence of general perceptions of the training environment on pretraining motivation and perceived training transfer, in Journal of Management 21(1): 1-25.

49. Bandura A (1986) Social Foundations of Thought and Action: A Social Cognitive Theory, Englewood Cliffs, Prentice Hall, New Jersey, United States.

50. Kraiger K, Ford JK, Salas E (1993) Application of cognitive, skill-based, and affective theories of learning outcomes to new methods of training evaluation. Journal of Applied Psychology 78(2): 311-328.

51. Brown TC (2005) Effectiveness of distal and proximal goals as transfer-of-training interventions: A field experiment. Human Resource Development Quarterly 16(3): 369-387

52. Kozlowski SWJ (2001) Effects of Training Goals and Goal Orientation Traits on Multidimensional Training Outcomes and Performance Adaptability. Organizational Behavior and Human Decision Processes 85(1): 1-31.

53. Gaudine AP, Saks AM (2004) A longitudinal quasi-experiment on the effects of posttraining transfer interventions. Human Resource Development Quarterly 15(1): 57-76.

54. Schwoerer CE, Douglas R May, Elaine C Hollensbe, Jennifer Mencl (2005) General and specific self-efficacy in the context of a training intervention to enhance performance expectancy. Human Resource Development Quarterly 16(1): 111-129.

55. Staples DS, Hulland JS, Higgins CA (1999) A self-efficacy theory explanation for the management of remote workers in virtual organizations. Organization Science 10(6): 758-776.

56. Hazucha JF, Hezlett SA, Schneider RJ (1993) The Impact of 360-Degree Feedback on Management Skills Development. Human Resource Management 32(2): 325-351.
57. Bell BS, Tannenbaum SI, Ford JK, Noe RA, Kraiger K (2017) 100 years of training and development research: What we know and where we should go. Journal of Applied Psychology 102(3): 305-323.

58. Tonhäuser C, Büker L (2016) Determinants of Transfer of Training: A Comprehensive Literature Review. International Journal for Research in Vocational Education and Training 3(2): 127-165.

59. Rahman AA, Shiddike MO (2020) Mixed methods in human resource development: Reviewing the research literature. International Journal of Business and Management 15(3): 25-36.

60. Shiddike MO, Rahman AA (2020) Case study method in human resource development: Reviewing the research literature. International Business Research 13(4): 113-124.

61. Hughes M (2013) Learner-controlled practice difficulty in the training of a complex task: Cognitive and motivational mechanisms. Journal of Applied Psychology 98(1): 80-98.

62. Savern LR, Andrew G, Lynn J (2017) Efficacy of low-cost PC-based aviation training devices. Journal of Information Technology Education: Research 16: 127-142.

63. Merschbrock C (2016) Serious games as a virtual training ground for relocation to a new healthcare facility. Facilities, 34(13/14): 788-808.

64. Robinson JC (1984) You should have sent my boss. Training 21(2): 4547.

65. Trost A (1982) They may love it, but will they use it? Training and Development Journal 36(1): 78-81.

66. Dragoni L, Lisa Oh, In-Sue Tesluk, Paul E Moore, Ozias A, VanKatwyk, et al. (2014) Developing leaders' strategic thinking through global work experience: the moderating role of cultural distance. Journal of Applied Psychology 99(5): 867-82.

67. Stephen H, Colbert AE, Choi D (2014) Fired up or burned out? How developmental challenge differentially impacts leader behavior. Journal of Applied Psychology 99(4): 681-696.

68. Noe RA, Clarke ADM, Klein HJ (2014) Learning in the twenty-first-century workplace. Annual Review of Organizational Psychology and Organizational Behavior 1(1): 245-275.

69. Brown KG, Charlier SD, Pierotti A (2012) e-learning at work: Contributions of past research and suggestions for the future, in International review of industrial and organizational psychology. In: Hodgkinson GP, Ford JK, (Eds.), Wiley: New York, pp. 89-114.

70. Stomp B (2019) Technology and training, in Propane Canada. Northern Star Communications Ltd. Calgary, Canada, pp. 6-7.

71. Kuemmerle JF (2012) Effective Use of Technology in Gastroenterology Training. Gastroenterology 143(4): 881-884.

72. Rahman AA, Shiddike MO (2019) Agendas for future training transfer research: Pakistan's perspective. Developing Country Studies 9(4): 3948.

73. Shiddike MO, Rahman AA (2019) Engaging faculty in professional development: Lessons from Bangladesh. Journal of Educational and Developmental Psychology 9(2): 124-137.

74. Bell BS, JE Federman (2013) E-learning in postsecondary education. The Future of Children 23(1): 165-185 
